DEPARTAMFNTO DE HISTOI.OGIA E EMIJRIOLOGIA

Diretor: Prof. Ir. Antonio G. Frri

\title{
ESTUDO MORFOLOGICO DOS PIGMENTOS ENCONTRADOS NO FÍGADO, BAÇO E RIM DE PEIXES DE ÁGUA DOCE* *
}

MORPHOLOGIC STUDIES OF THE PIGMENTS FOUND IN LIVER. SPLEEN ANI KIDNEY OF FRF.SH WATER FISHI

Mikico Toklahio Instrutor
Heilorsi Gonnio **

Como parte de um programa de trabalhos destinados a elucidar problemas referentes aos peixes, são aqui apresentados os resultados das observaçōes realizadas em tecidos desses animais, onde com freqüiencia abundam os pigmentos, substâncias estas cuja natureza ainda ć objeto de discussão na literatura especializada.

Parece ter sido Aunicé (1), em 1910, um dos primeiros a fazer referência a pigmentos no rim de teleósteos, sem contudo classificá-los. Verse (11), em seu tratado sôbre pigmentos dos animais, apesar de referir-se, também, aos encontrados em peixes, silencia quanto à presença de cromolipóides em órgãos internos, exceto nas células nervosas.

Posteriormente, algumas observações apareceram sôbre o assunto, sendo os pigmentos classificados genèricamente entre os cromolipóides $(3,14,15)$, ou mais especificamente como ceróide (8), ou ainda sem possibilidade de identificação (16).

Mazż (6) julga existirem pelo menos três tipos diversos de pigmentos nos órgãos internos de peixes e, finalmente, Woon e YASUTAKE (12) pensam que o pigmento encontrado é ceroidico, aparecendo, entretanto, sómente $\mathrm{em}$ diferentes condiçōes patológicas.

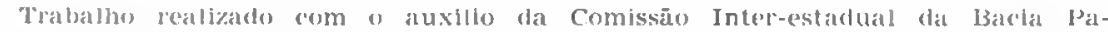
ranà-l’ruguali

* Biologista do Departamento de Produção Animal, da Secretaria da Agricultura do Estado de sāo Paulo. 


\section{MATERIAL E, MFTOIOS}

Neste trabalho foram utilizados 15 exemplares de peixes de ambos os sexos, das seguintes espécies: Pimolodus maculatus (mandi), Prochilohus scroja (curimbatá) e Cymrims carvio (carpa), gentilmente cedidos pela Divisão de Proleção e Produção de Peixes e Animais Silvestres, do Departamento de Produção Animal, da Secretaria da Agricultura do Estado de São Paulo.

Os animais, transportados em latóes especiais para o labor'atório, foram sacrificados por comoção cerebral e necropsiados imediatamente por incisāo longitudinal, na linha ventral. Após a retirada das visceras, coletaram-se fragmentos de fígado, baço e rim, com cêrca de $2-3 \mathrm{~mm}$ de espessura, os quais for'am fixados por 12 horas aproximadamente em formol a $10 \%$, , lamponado a pH 7, Bouin, Susa e a mistura aconselhada por Toktariat e col. (10).

Procedeu-se depois dos tratamentos adequados à inclusão em parafina, microtomia com $5 \mu$ de espessura e coloração pela H.E.

\section{RESULTAIXOS}

A ouservação microscópica dos cortes histológicos corados pela hematoxilina-eosina revelou que sistemáticamente no figado, baco e no tecido pancreático, que acompanha os vasos désses órgãos, bem como no rim e de modo ocasional em outros tecidos, encontram-se pigrmentos de color'ação amarelo-acastanhada, cuja tonalidade pode apresentar grande variação.

Os pigmentos apresentam-se como grânulos grosseiros de forma arredondada, mostrando r'efringência esverdeada a grandes aumentos e que aparentemente podem coalescer para formar glóbulos de aspecto homogênco, os quais se mostram, às vêzes, facetados e em geral, ao que parece, envolvidos por uma membrana.

Mostram-se formando conglomerados de vários tamanhos entre cólulas do parênquima ou no seio do tecido conjuntivo, onde, não raramente, são envoltos por membrana ou por cảpsula.

Nestas localizaçōes, com mais freqüência os pigmentos são observados no interior de cólulas aparentemente já sem núcleo, ou são extra-celulares.

Concomitantemente são os mesmos encontrados dispersos no citoplasma das células parenquimatosas ou ainda, no interior de macróf agos. 
Nestes últimos, qualquer que seja o tecido, as células se mostram arredondadas com os núcleos rechaçados para a periferia ou mascarados pela cuantidade de grânulos pigmentários.

Deve-se mencionar ainda que muitas vèzes, encontram-se pigmentos livres e isolados, dispersos pelo tecido.

No figado e parte disseminada do pâncreas, encontram-se estas substáncias formando acúmulos ou nódulos de tamanhos variados entre as células hepáticas ou pancreáticas, bem como no seio do tecido conjuntivo dos espaços de Kiernan, no perivascular e também no que acompanha os condutos biliares.

Não raras vêzes tem-se a impressão de que a massa de pigmentos é envôlta por membrana de aspecto endotelial, não sendo, entretanto, possivel em microscopia óptica estabelccer-se com precisāo a natureza da estrutura envolvente.

Concomitantemente ou nāo com o aspecto descrito, encontram-se g!ânulos pigmentảrios dispersos no citoplasma dos hepatócitos, às vêzes, de modo abundante, outras em pequena quantidade e tambem livres e esparsos por todo o tecido. Em alguns

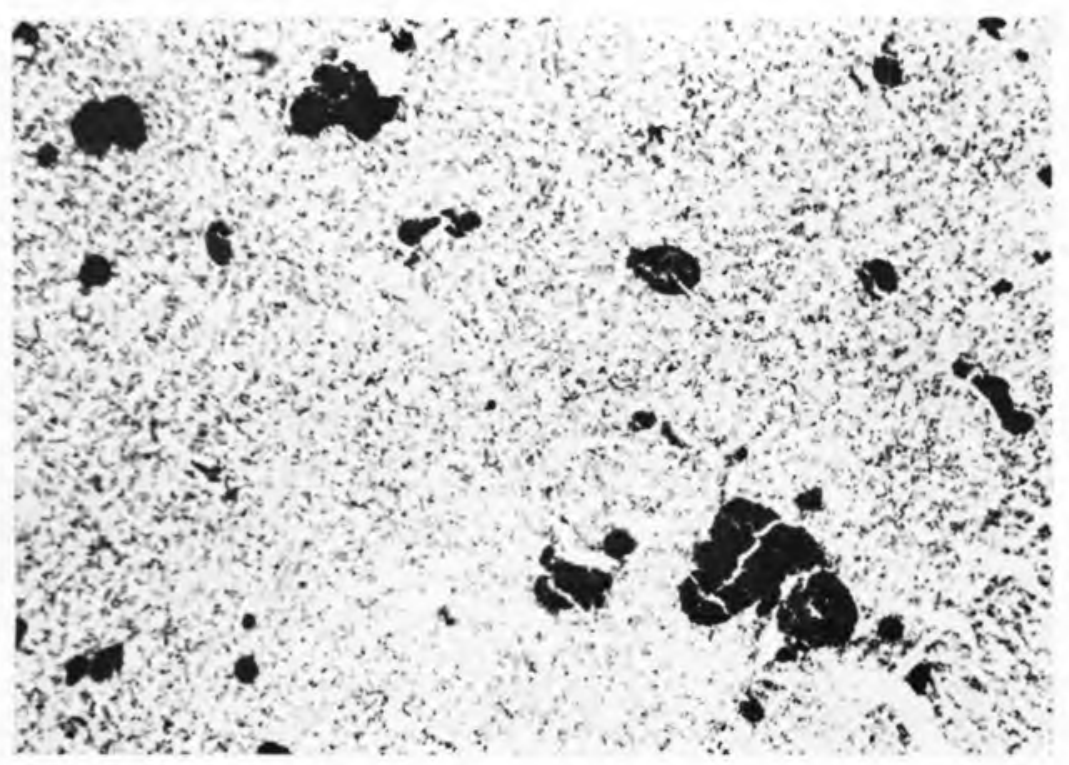

Fig. 1 - Figado de $P$. scrofa onde se observa grande quantidade de plymentos, em geral formado conglomerados. II. E. - 120 X. 
casos aparcem os mesmos no interior de macrófagos, que formam ninhos celulares no seio do conjuntivo perivascular ou peritubular. Tanto quanto foi po.sisivel verificar, as células de Küpffer em nenhum dos casos se apresentam com pigmentos.

No baço, os pigmentos aparecem livres ou em quantidade variável no interior de células reticulares, as quais se encontram isoladamente no seio do tecido, ou formando verdadeiros nódulos, de modo particular junto às paredes vasculares. Em alguns casos, também no tecido pancreático intra-esplênico são observados um ou outro macrófago com granulação pigmentária, entre as células déste tecido.

Simultâneamente com estes aspectos se en ontram conglomerados de tamanhos diversos no tecido esplênico, os quais se mostram limitados apenas por cólulas dêste tecido, sendo, entretanto, às vêzes, envoltos por membrana de aspecto endotelial ou mesmo por delicada cápsula conjuntiva.

No rim, os acúmulos de pigmentos em pequena ou grande quantidade aparecem no seio do tecido linfóide intertubular. Estas massas pigmentárias afastam as células linföides, ficando pelas mesmas circundadas, havendo entretanto, algumas veres, como nos casos anteriores, membrana ou cápsula envolventes com aspectos já descritos.

Os pigmentos são, de modo mais raro, encontrados no tecido conjuntivo perivascular, periglomerular e umas poucas vêzes, também ao redor de lúbulos.

Ainda neste órgão, se verifica juntamente com estas formaçōes, pigmentos dispersos no tecido, ou no interior de macrófagos, no conjuntivo de cápsula renal, onde estas células são mais fàcilmente identificadas.

Por último, cm certos casos, os grânulos pigmentários são encontrados no inter ior de células nos glomérulos ou dispersos no citoplasma de células tubulares.

\section{I) ISCUSS UNO}

O estudo dos pigmentos encontrados nos tecidos dos animais tem merecido a atenç̃o de inúmeros pesquisadores, mas apesar das modernas técnicas histoquimicas ou mesmo da microscopia eletrônica, muitos sĩo os problemas que persistem, demandando novas investigacooes, o que bem demonstra a complexidade do assunto 
Em peixes, não há ainda acôrdo entre os autores sôbre a natureza e origem dessass substâncias encontradas no fígado, baço e rim, em diferentes espécies, pensando alguns pesquisadores que as mesmas são varificáveis sỏmente eñ condicōes patológicas 18 , 12).

Nossas observações revelaram sua presença nesses órgāos, em maior ou menor quantidade, de modo sistemáiico, em animais que aparentemente não portavam nenhuma afecção.

Quanto à natıreza dêsses pigmentes, existem divergências entre os que se têm dedicado ao problema $(1,6,8,12,16)$, o que certamente decorre, em parte, pela diversidade de espécies com que trabalharam, e em parte, pela variação de comportamento dos grânulos pigmentários, frente aos mesmos festes de solubilidade, descoramento ou reações histoquímicas, ainda que na mesma preparaçõo hrolóǵgina, como tivemos oportunidade de observar (9).

Estes falos têm dificultado grandemente a interpretação dos resultados obtidos por diferentes pesquisadores, agregando-se, ainda, as divergências existentes quanto à nomenclatula entre os vários tratadistas $(2,4,5,7)$.

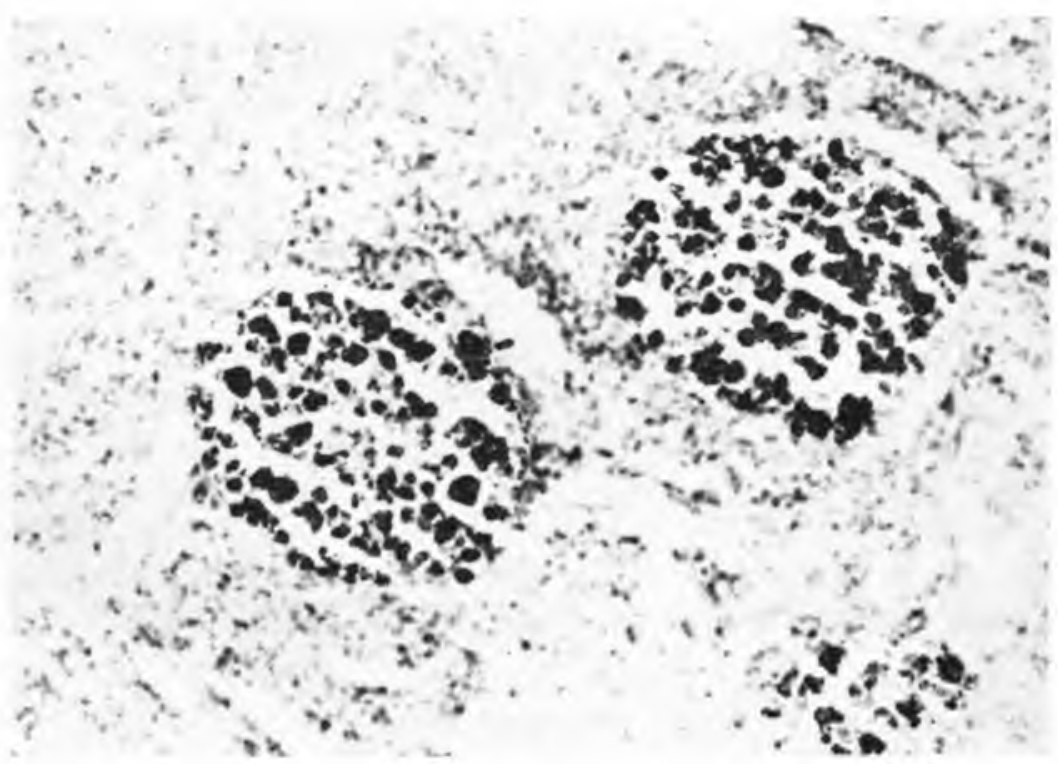

Fig. 2 - Baco de $P$. scofofa no qual se observam cunglomerados de pigmentus circundados por membrana de aspecto endotelial. II.6. $-300 \mathrm{X}$ 
Deve-se, finalmente, mencionar que os aspectos morfológicos observados no fígado, baço e rim das espécies estudadas assemelham-se aos descritos na espécie humana nos chamados nódulos de Gandy-Gamna (13) sendo, portanto, ao que parece, excelente material para pesquisas, orientadas no sentido de esclarecer sua natureza c gênese.

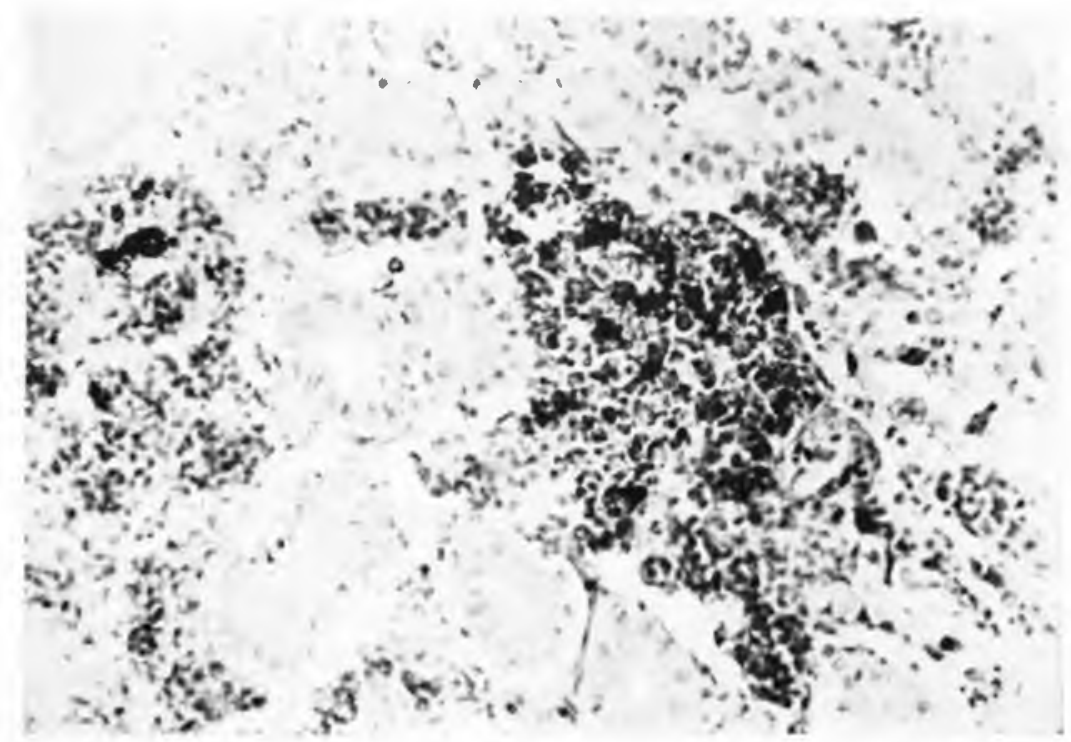

Fig. 3 - Rim de $P$. scrofa no qual se observam pigmentos no lecilo linfoide e nas células tubulares. 11.t. 310 $\mathrm{x}$.

\section{SUMÁRIO}

É descrito o aspecto microscópico dos pigmentos encontrados no figado, baço e rim de Pimelodus muculatus, Prochilodus scrofa e Cyprimus carpio, observado por métodos rotineiros de técnica histológica. Verificoul-se que esses pigmentos podem apresentar disposição a dos nódulos de Gandy-Gamna, descritos no homem, e sua presença é notada em tecidos aparentemente normais.

\section{SLMMARY}

In this paper, the author's study, the pigments found in the liver, spleen and kidney of the Pimclodus maculatus. Prorhilodus 
scroja and cyprinus carpio, describing the morphological aspects observed by histological techniques.

They conclude that pigments in the tissues studies form conglomerates similar to the Gandy-Gamna nodules described in humans.

Howerer, in the fish tissues studied, the pigments are found as a normal condition.

\section{REFERENCIAS TIBLIOGRAEICAS}

1. AlDIGÉ, J. - 1910 - Contribution à l'étude des reins des Poissons 'Téléostẻens. Arch. Zoo. Exp. et Gen., Paris, 5ème scric, 4:275-624.

2. BARKA, T. \& ANDERSON, P. J. - 1965 - Histochemistry: Theory, practice and bibliography. New York. Hocber Medical Division.

3. BIGNARDI, C. - 1947 - Cellule a cromolipoide nella cistifellea di Esor lucius c loro particolarita istochimiche. Arch. It. di Anat. e Embr., Firenze, $52: 258$.

4. III.L.IF, R. D. - 1954 Histoputhologic fechnic and practical histochemistry. New York. Blakiston.

5. IISON. I. - $1960-$ Histochimie et cytochimie animales, 3 éd. Paris, Gauthier Villars.

6. MAZZI. V. - 1955 - La cellule a pigmenti nel tessuto linfoide del rone medio di Cyyminus carpio I. Arch. Zool. (ital.) Napoli, fo:347359.

7. PEARSE: A. G. I. - 1961 - Histochemistry: theorical and applied. 2nd. cd. Gloucester. J. E. A. Churchill.

8. PICKFORD, G E. 1953 - A study of the hypophysectomized male killifish. Fundulus heteroclitus (I.inn.) Bull. Binghum Oceunogr. Coll., New Hav'en, $1 / 4(2): 5-41$.

9. TOKIMMARU, M. \& FERRI, A. G. - Estudo histoquimico dos pigmentos encontrados no rígado, baço e rim de peises de água doce ra ser publicado).

10. TOKIMARU, M.; GODINHO, H. \& FFRRI. A. G. - 1968 - Fixa(cão de tecidos de prixes de água duce. Rev Fuc. Med. Vet., São Paulo. ก(1):8:11-848.

11. VERNE: J. - 1926 - Le's pigments dens forganisme animal. Paris, Gaston Doin.

12. WOOD. F. M. \& YASUTAKE. W. Y. - 1956 - Ceroid in fish. Amer. J. Puthol, New Yolk, 3:(1-3):591-603. 
13. ZAMPI, G. - $19 \overline{5} 4-$ I rapporti fra (mosiderina e cromolipoidi ferruginosi nello studio istochimico delle aree di Gamna spleniche e in sed extra-lienalc. Arch. De Vecchi., Firenze, 22(1):255-279.

14. ZOCCHI, P. - 1953 - Contributo alla conoscenza istochimica de] cromolipoide della cistifellea di Esox lucius. Monil. zon?. Itul. Firenze. $61: 80-83$.

15. ZOCCHI, P. - 1954 - Osservazioni preliminari su una sostanza lipidica Hotchkiss positiva nell'epitelio della cistifellea di Esos lucius. Honit. sool. ital.. Firenze, 62:111-113.

16. 7ORZOLI, G. C. \& SBEIRNINI, C. - 1954 - Ricerche istochimiche sul pigmento rresente nei tubuli renali di Esox lucius. Monit. oool. ital, Firenze, $6: 3$ (supple) : 403-408. 